\title{
EXPERIMENTAL STUDY OF DEFORMATION BEHAVIOR AND FATIGUE LIFE OF AISI 304 STAINLESS STEEL UNDER AN ASYMMETRIC CYCLIC LOADING
}

Yung-Chuan Chiou

Department of Biomechatronic Engineering, National Chiayi University, Chiayi, Taiwan., solas@mail.ncyu.edu.tw

Follow this and additional works at: https://jmstt.ntou.edu.tw/journal

Part of the Engineering Commons

\section{Recommended Citation}

Chiou, Yung-Chuan (2010) "EXPERIMENTAL STUDY OF DEFORMATION BEHAVIOR AND FATIGUE LIFE OF AISI 304 STAINLESS STEEL UNDER AN ASYMMETRIC CYCLIC LOADING," Journal of Marine Science and Technology. Vol. 18:

Iss. 1, Article 15.

DOI: $10.51400 / 2709-6998.1873$

Available at: https://jmstt.ntou.edu.tw/journal/vol18/iss1/15

This Research Article is brought to you for free and open access by Journal of Marine Science and Technology. It has been accepted for inclusion in Journal of Marine Science and Technology by an authorized editor of Journal of Marine Science and Technology. 


\title{
EXPERIMENTAL STUDY OF DEFORMATION BEHAVIOR AND FATIGUE LIFE OF AISI 304 STAINLESS STEEL UNDER AN ASYMMETRIC CYCLIC LOADING
}

\author{
Yung-Chuan Chiou*
}

Key words: fatigue life, cyclic stress response curve, mean strain effect, AISI 304 stainless steel.

\begin{abstract}
In this study, the cyclic deformation behavior and fatigue life of AISI 304 stainless steel with or without mean strains were studied experimentally. In the case of fully reversal cyclic straining, it is found that there is no virtually difference between the cyclic stress response curves in tension and in compression at strain amplitude of higher than $0.30 \%$. At the controlled strain amplitude of $0.25 \%$ and $0.30 \%$, the two cyclic stress response curves are separated quite widely. The degree of asymmetry can be attributed to the anisotropic behavior of AISI 304 stainless steel. Further, the experimental results indicate that AISI 304 stainless steel has a cyclic softening characteristic and exhibits Massing behavior at controlled strains amplitudes of higher than $0.35 \%$. Meanwhile, in investigating the influences of mean strain on the cyclic deformation behavior and fatigue life, a cyclic-dependent relaxation of the mean stress occurs and the stable mean stress exerts a relatively greater effect on the fatigue life. In this study, both damage parameters are applied to the predictions of fatigue life in term of life prediction. From a comparison between the experimental and the predicted fatigue life, the both damage parameters provide reasonable life predictions and found that the $\left(\sigma_{\max } \varepsilon_{a}\right)_{p}$ parameter possess a better ability than the SWT damage parameter.
\end{abstract}

\section{INTRODUCTION}

The material properties obtained from fully-reversed fatigue testing under total strain-controlled conditions are of fundamental importance when designing components which

Paper submitted 07/16/08; accepted 03/26/09. Author for correspondence: Yung-ChuanChiou, (e-mail: solas@mail.ncyu.edu.tw).

*Department of Biomechatronic Engineering, National Chiayi University, Chiayi, Taiwan. are expected to experience repeated loading during their service lives many studies [3-5, 9, 12, 14, 17-18, 21, 23-24] have been performed to investigate the cyclic response of materials subjected to cyclic inelastic loading. However, most service applications involve non-zero mean cyclic straining or stresses. Consequently, the effects of non-zero mean strain or stress on the fatigue resistance of a material must be taken into account when modeling the response of machine components under normal operating conditions or in the event of an accident. However, most service applications involve non-zero mean cyclic straining or stresses. Consequently, the effects of non-zero mean strain or stress on the fatigue resistance of a material must be taken into account. In the case of an applied tensile mean stress, the fatigue life is found to reduce and the degree of the mean stress effect on the fatigue life is governed by the magnitude of the mean stress. Furthermore, in the strain-controlled case, a cyclic-dependent relaxation of the mean stress is observed when the specimen is subjected to asymmetric cyclic straining. It has been reported that the degree of relaxation of the mean stress depends on the combined effects of the mean strain component and the alternating strain component [2]. Several studies [6, 11-12, 15, 25] have shown that the effect of mean strain on the fatigue life is determined primarily by the presence (or absence) of a stable non-zero mean stress. In term of fatigue life prediction, several empirical expressions have been proposed when a mean stress effect is present $[7-8,19,22,26]$. In those proposed expressions, the Smith, Watson and Topper model (commonly referred to as the SWT model) is most widely applied since it is generally successful in predicting the effects of mean stress/strain on the low and high cycle fatigue response of a variety of materials $[1,13,15-16,20,25]$. The SWT model assumes that the fatigue life under any mean stress condition depends on the product of stable maximum stress and strain amplitude, $\sigma_{\max } \varepsilon_{a}$, (defined as the SWT parameter) and is same as for fully reversed loading when the product has the same value. In this paper, the fatigue response of AISI 304 stainless steel is observed under various combinations of alternating and mean strain. Simultaneously, the SWT parameter and plastic strain energy in the SWT parameter, $\left(\sigma_{\max } \varepsilon_{a}\right)_{p}$, are ap 
Table 1. Chemical composition of AISI 304 stainless steel (weight \%).

\begin{tabular}{ccccc}
\hline $\mathrm{C}$ & $\mathrm{Si}$ & $\mathrm{Mn}$ & $\mathrm{P}$ & $\mathrm{C}$ \\
\hline 0.05 & 0.33 & 1.73 & 0.032 & 0.05 \\
\hline $\mathrm{Si}$ & $\mathrm{Mn}$ & $\mathrm{P}$ & $\mathrm{Fe}$ & \\
\hline 0.33 & 1.73 & 0.032 & bal. & \\
\hline
\end{tabular}

Table 2. Summary of mean value of the experimental data obtained from fully-reversed fatigue tests for AISI 304 stainless steel.

\begin{tabular}{crccc}
\hline$\varepsilon_{a}$ & $\sigma_{\text {mean }}$ & $100\left(\sigma_{\max } \varepsilon_{a}\right)$ & $100\left(\sigma_{\max } \varepsilon_{a}\right)_{p}$ & $N_{f}$ \\
\hline$\%$ & $\mathrm{MPa}$ & $\mathrm{Mj} / \mathrm{m}^{3}$ & $\mathrm{Mj} / \mathrm{m}^{3}$ & Cycles \\
\hline 0.35 & -0.91 & 125.45 & 60.96 & 40177 \\
0.40 & 0.74 & 144.27 & 79.18 & 22363 \\
0.45 & -1.52 & 166.19 & 96.68 & 12601 \\
0.50 & 0.47 & 187.47 & 119.17 & 8862 \\
0.60 & 0.77 & 229.73 & 159.02 & 4803 \\
0.70 & -0.62 & 278.78 & 204.59 & 2631 \\
\hline
\end{tabular}

plied to develop fatigue life predictions for AISI 304 stainless steel. The predicted fatigue life results are then compared with the experimental results.

\section{EXPREIMENTAL PROCEDUE}

This study analyzes the deformation behavior of AISI 304 stainless steel cyclic straining with or without mean strains. Table 1 presents the chemical composition of the as-received AISI 304 stainless steel. To investigate the effects of mean strain on the cyclic deformation behavior and fatigue resistance of AISI 304 stainless steel, strain-controlled low cycle fatigue tests were conducted at mean strain levels of $\varepsilon_{m}=0.5 \%$, $0.2 \%, 0 \%$, and $-0.1 \%$, respectively, with strain amplitudes ranging from $0.35 \%$ to $0.70 \%$. All fatigue tests are performed at a constant strain rate of $10^{-2} \mathrm{~s}^{-1}$ and a triangular waveform. Each fatigue test was continued until the specimen failed. The fatigue life, $N_{f}$, of each specimen was defined as the number of applied cycles corresponding to a $10 \%$ reduction in the maximum load on the recorded cyclic-load-response curve. The longitudinal strain was measured continuously throughout each test using a longitudinal extensometer with a $25 \mathrm{~mm}$ edge separation clamped to the specimen. Table 2 summarizes the experimental results obtained from the fully reversal fatigue tests at each of the specified strain levels. The experimental results with a non-zero mean strain are summarized in Table 3.

\section{RESULTS}

\section{Cyclic Deformation Behavior Under Symmetric Cyclic Straining}

Figures 1(a)-1(h) present the cyclic stress response curves for AISI 304 stainless steel under fully-reversed cyclic strain-
Table 3. Summary of mean value of the experimental data obtained from fully-reversed fatigue tests for AISI 304 stainless steel with imposed mean strain.

\begin{tabular}{|c|c|c|c|c|}
\hline$\varepsilon_{m}$ & $\sigma_{\text {mean }}$ & $100\left(\sigma_{\max } \varepsilon_{a}\right)$ & $100\left(\sigma_{\max } \varepsilon_{a}\right)_{p}$ & $N_{f}$ \\
\hline$\%$ & $\mathrm{MPa}$ & $\mathrm{Mj} / \mathrm{m}^{3}$ & $\mathrm{Mj} / \mathrm{m}^{3}$ & Cycles \\
\hline \multicolumn{5}{|c|}{$\varepsilon_{a}=0.35(\%)$} \\
\hline 0.50 & 17.86 & 131.03 & 64.42 & 27708 \\
\hline 0.20 & 6.09 & 127.00 & 62.61 & 35528 \\
\hline-0.20 & -8.37 & 127.15 & 59.52 & 48622 \\
\hline \multicolumn{5}{|c|}{$\varepsilon_{a}=0.40(\%)$} \\
\hline 0.50 & 9.93 & 149.04 & 82.15 & 17581 \\
\hline 0.20 & 3.80 & 147.37 & 81.46 & 19773 \\
\hline-0.20 & -4.62 & 149.22 & 79.66 & 22031 \\
\hline \multicolumn{5}{|c|}{$\varepsilon_{a}=0.45(\%)$} \\
\hline 0.50 & 7.87 & 170.34 & 101.23 & 11734 \\
\hline 0.20 & 2.12 & 167.36 & 99.99 & 11290 \\
\hline \multicolumn{5}{|c|}{$\varepsilon_{a}=0.50(\%)$} \\
\hline 0.50 & 3.22 & 191.35 & 120.42 & 8171 \\
\hline 0.20 & 0.36 & 187.80 & 120.35 & 9406 \\
\hline-0.20 & -1.61 & 195.32 & 120.95 & 8734 \\
\hline \multicolumn{5}{|c|}{$\varepsilon_{a}=0.60(\%)$} \\
\hline 0.50 & 0.25 & 234.28 & 163.90 & 4694 \\
\hline 0.20 & -0.06 & 233.47 & 161.82 & 4854 \\
\hline-0.20 & -1.54 & 239.76 & 163.85 & 5042 \\
\hline \multicolumn{5}{|c|}{$\varepsilon_{a}=0.70(\%)$} \\
\hline-0.20 & -2.08 & 286.70 & 208.00 & 2282 \\
\hline
\end{tabular}

ing at eight different total strain amplitudes. These figures indicate that the peak stress increases rapidly in the first few cycles and then reduces gradually as an increasing number of cycles are applied. Meanwhile, during the early stages of cycling, a cyclic softening behavior is evident and more significant at higher total strain amplitudes. To further analyze the symmetry between the cyclic stress response curves in tension and in compression, as shown in Figs. 1(a)-1(h), the relevant peak stress data in absolute value form is plotted against the corresponding number of fatigue cycles at various total strain amplitudes. In Figs. 1(a) and 1(b), it can be seen that the two cyclic stress response curves are separated quite widely and it is evident that the cyclic stress response curve in compression is higher than that in tension. The separation between the two curves is smaller at a strain amplitude of $0.30 \%$ compared to a strain amplitude of $0.25 \%$. Hence, it can be inferred that the anisotropic mechanical response of AISI 304 stainless steel can be not neglected during cyclic deformation performed at controlled total strain amplitudes of $0.25 \%$ and $0.30 \%$. Simultaneously, it can be seen that the degree of asymmetry depends on the magnitude of the total strain amplitude. Furthermore, Figs. 1(c)-1(h) show that there is virtually no difference between the cyclic stress response curves in tension and those in compression. The observations above indicate that the stable hysteresis loops for AISI 304 stainless steel are almost symmetrical with respect to their tension and com- 


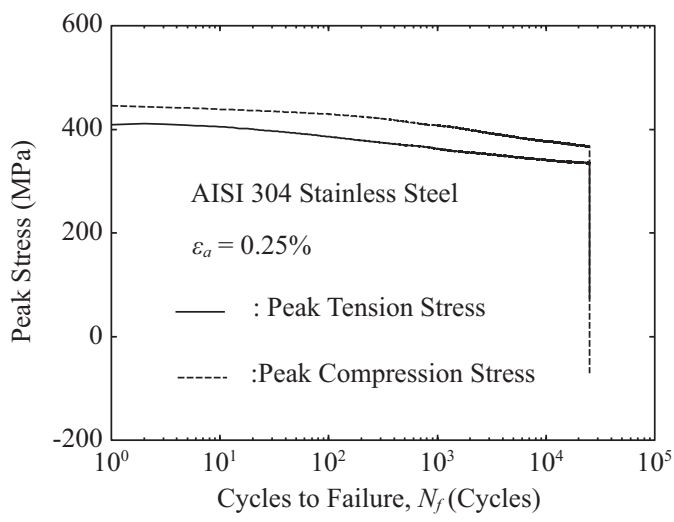

(a)

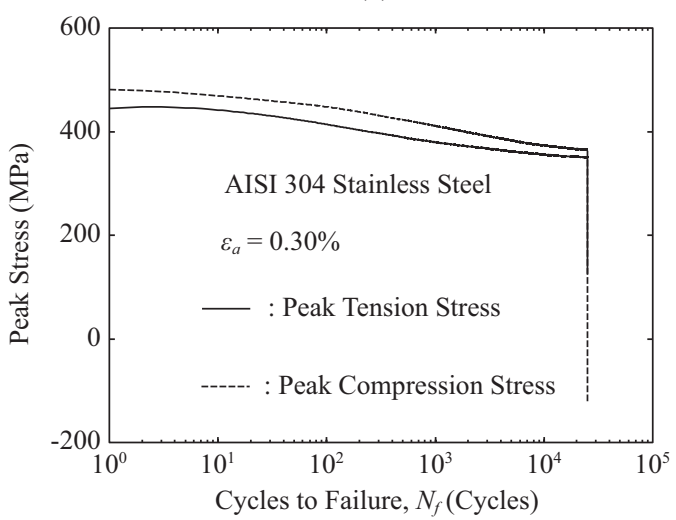

(b)

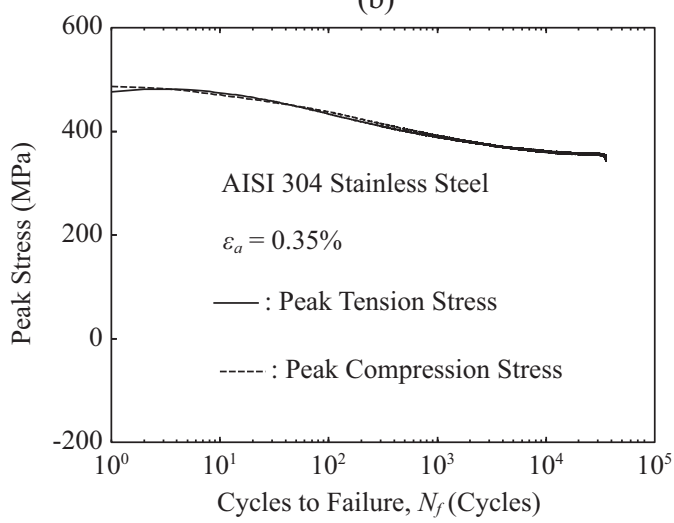

(c)

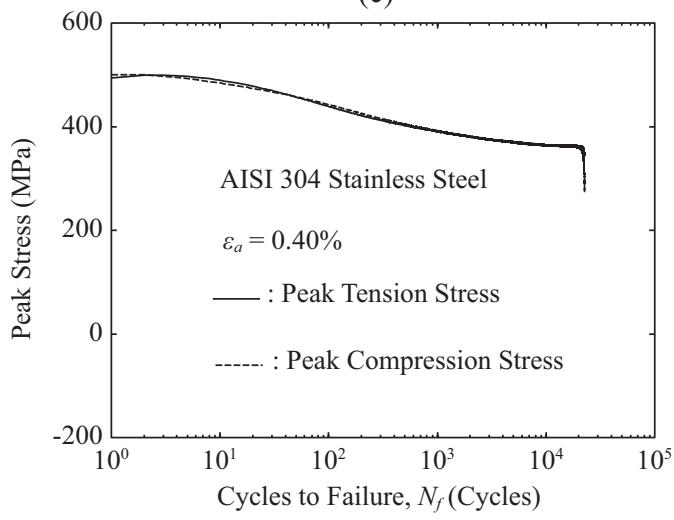

(d)

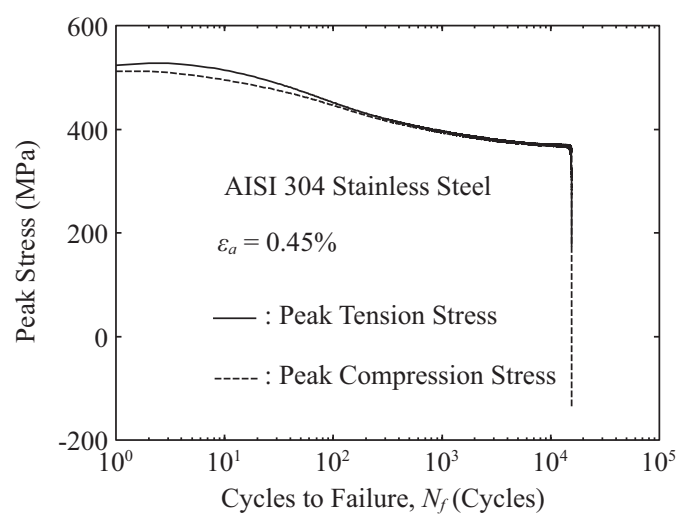

(e)

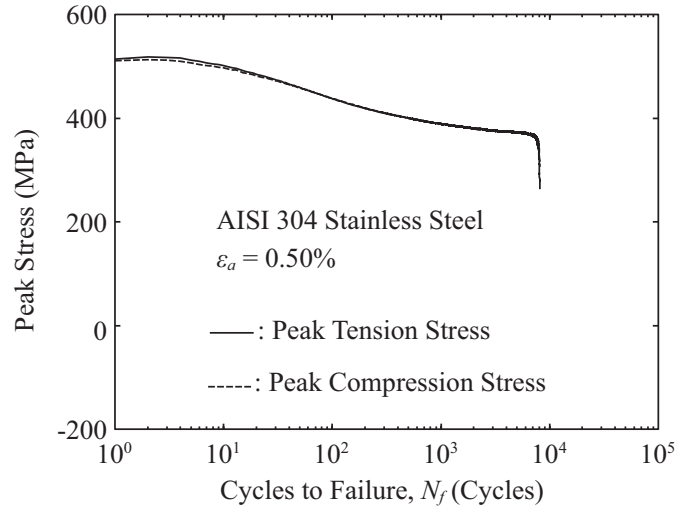

(f)

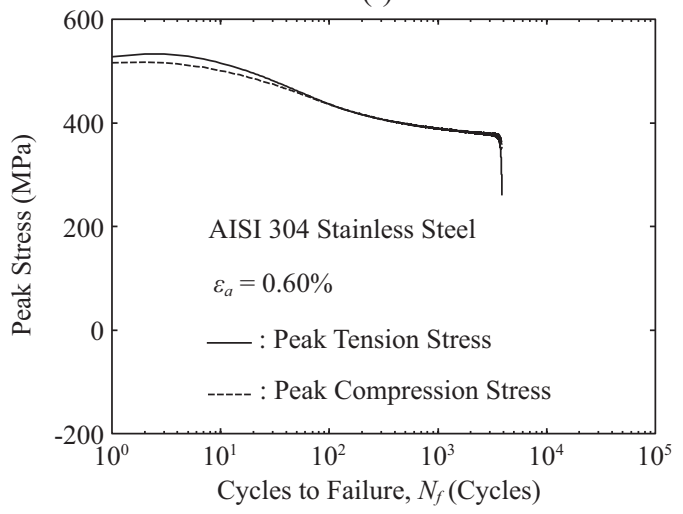

(g)

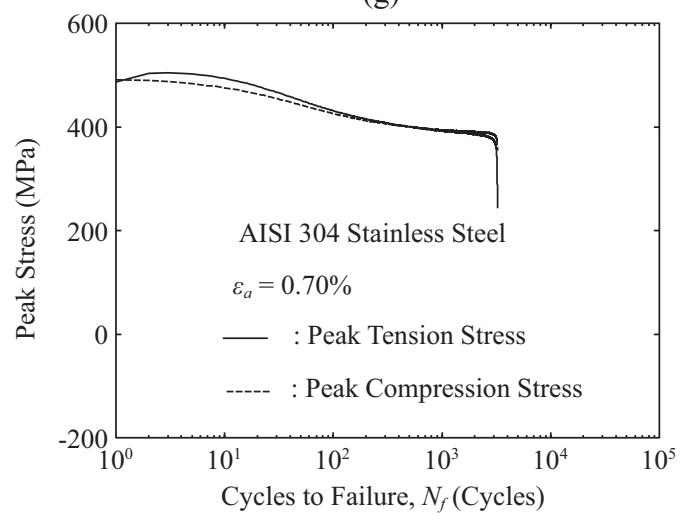

(h)

Fig. 1. *Stress response curves showing variations of tensile and compressive stress with number of cycles for AISI 304 stainless steel at strain amplitudes of: (a) $0.25 \%$, (b) $0.30 \%$, (c) $0.35 \%$, (d) $0.40 \%$, (e) $0.45 \%$, (f) $0.50 \%$, (g) $0.60 \%$, and (h) $0.70 \%$. 


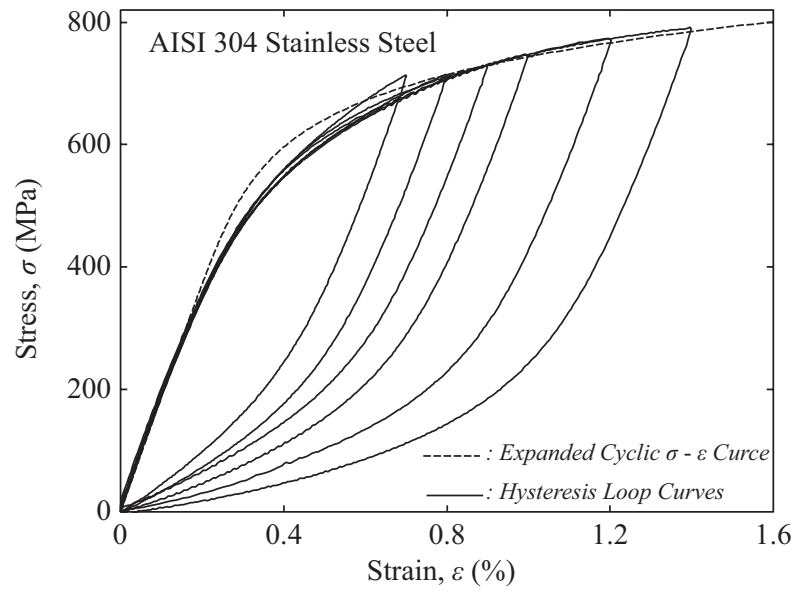

Fig. 2. Stable hysteresis loops for AISI 304 stainless steel plotted with shifted axes such that compressive tips coincide.

pression branches in most of the current fatigue tests. Figure 2 presents the superimposed stable hysteresis loops with coincident compressive tips. It can be seen that the loading curves for all of the hysteresis loops other than that relating to a strain amplitude of $0.35 \%$ fall on approximately the same locus. Therefore, it can be concluded that AISI 304 stainless steel exhibits Massing behavior at all of the considered strain amplitudes other than that of $0.35 \%$.

Generally, the strain-life curve can be used in a strain-based approach to generate fatigue life predictions and constructed by relating the strain amplitude, $\varepsilon_{a}$, to the number of cycles to failure, $N_{f}$. A simple power function is generally used to represent the strain-fatigue life curve. From an analysis of the present results, it is found that the relationship between the fatigue life and the total strain amplitude for AISI stainless steel is given by:

$$
\varepsilon_{a}=5.1896\left(N_{f}\right)^{-0.2568}
$$

Figure 3 show the simulated curve utilized (1) for the strain-life curve and experimental data pertaining to the current fully-reversed cyclic fatigue tests. It is apparent that a good agreement exists between the simulated curve and experimental data. Noted that the plotted data values in Fig. 5 are obtained by performing a mean value calculation on the results under same experimental conditions.

\section{Effects of Mean Strain on Cyclic Deformation and Fatigue Life}

Table 3 summarizes the strain amplitude, the mean strain level, the stable mean stress and the number of cycles to failure for each of the current fatigue tests performed with a non-zero mean strain. Figure 4 shows the variation of the recorded peak stresses in tension and compression, and the variation of the calculated mean stress, with the number of cycles performed at a mean strain level of $0.50 \%$ and a total strain amplitude of $0.35 \%$. It is observed that the imposed

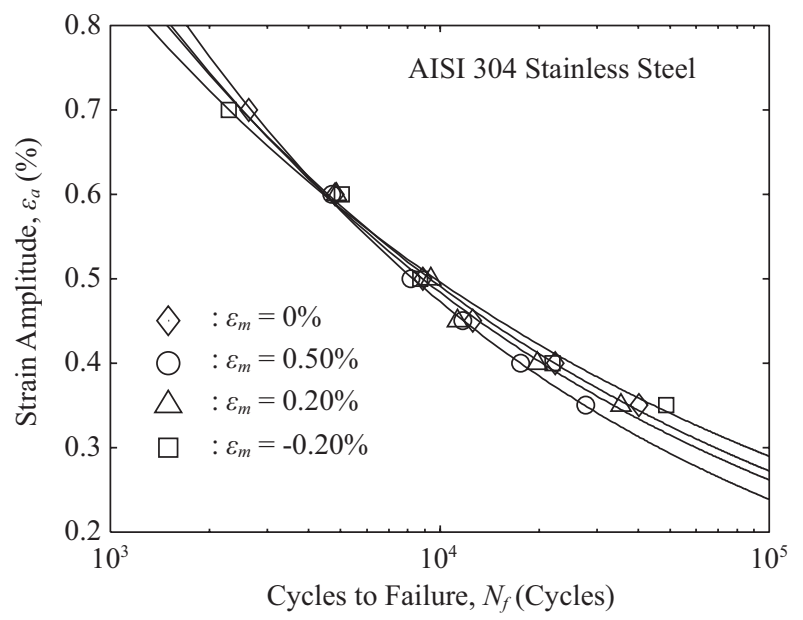

Fig. 3. Effects of non-zero mean strain on strain-life curve of AISI 304 stainless steel.

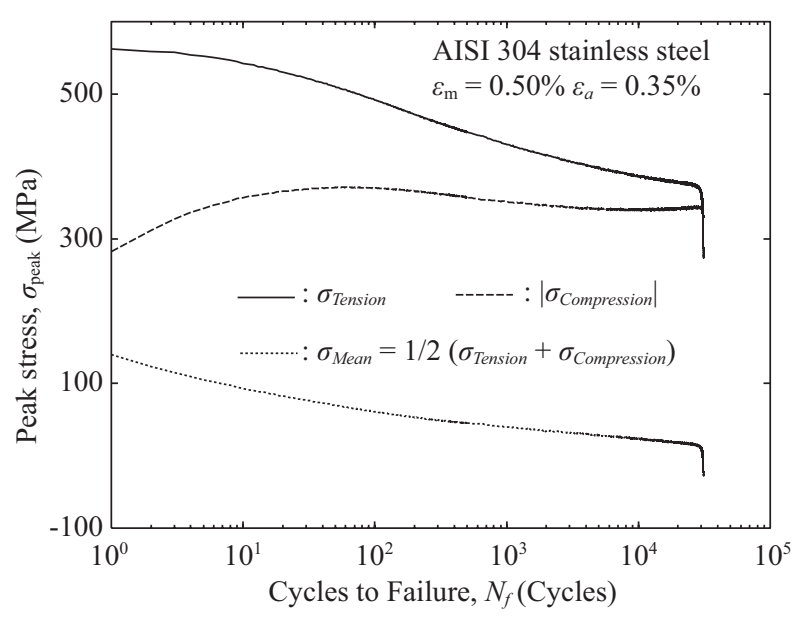

Fig. 4. Cyclic stress-response curves in compression and in tension and mean stress relaxation curve of AISI 304 stainless steel.

mean strain causes a mean stress relaxation effect. In this case, the stable mean stress does not fully relax. Figure 5 illustrates the fatigue life of AISI 304 stainless steel at various values of stable mean stress under the action of an imposed mean strain. It is apparent that the imposed mean strain has almost no effect on the fatigue life when the relaxed stable mean stress approaches to the range from $5 \mathrm{MPa}$ to $-5 \mathrm{MPa}$. However, if a stable non-zero mean stress exists other than the aforementioned stress range, the mean strain affects the fatigue life to an extent which is determined by the magnitude of the stable mean stress.

\section{DISCUSSION}

\section{Cyclic Stress-strain Curve and Stable Hysteresis Curve Determination}

Conventionally, the stable behavior of a material is represented by the hysteresis loops obtained at half fatigue life. In 


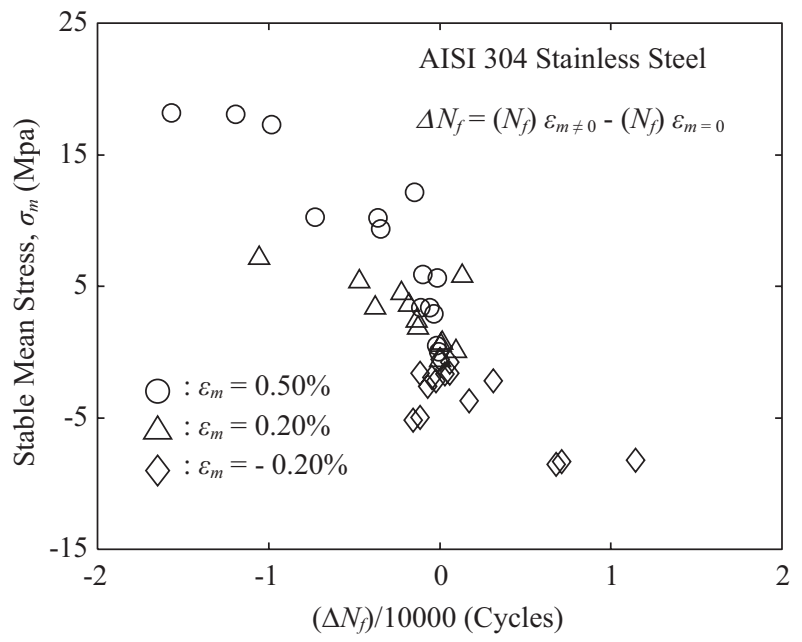

Fig. 5. Influence of stable mean stress on fatigue life of AISI 304 stainless steel with an non-zero mean strain level.

constructing the cyclic stress-strain curve, the hysteresis loops obtained from fatigue tests performed at various strain amplitudes are plotted on a single set of axes with their origins shifted to zero strain such that they are superimposed. The locus of the tips of the individual stable hysteresis loops represents the cyclic stress-strain curve. In other words, this linked curve indicates the correlation between the stress amplitude and the strain amplitude for cyclic loading. If the tension and compression branches of the applied hysteresis loops are symmetrical, then the cyclic stress strain curves in tension and compression are symmetric about the origin of the axes. The cyclic stress-strain curve is generally expressed as:

$$
\varepsilon_{a}=\frac{\sigma_{a}}{E}+\left(\frac{\sigma_{a}}{K}\right)^{1 / n^{*}}
$$

The values of $K$ and $n^{*}$ can be obtained from the simulated results for the cyclic stress-strain curve. In this study, the value for $K$ is 707.52 and for $n^{*}$ is 0.1108 . It is known that when Massing behavior is evident in a material, the stress-strain path for the stable hysteresis loops should have the same shape as the path obtained by expanding the cyclic stress-strain curve using a scaling factor of two. Hence, the tension branch of the stable hysteresis loop is described by:

$$
\Delta \varepsilon=\frac{\Delta \sigma}{E}+2\left(\frac{\Delta \sigma}{2 K}\right)^{1 / n^{*}}
$$

where the variables $\Delta \varepsilon$ and $\Delta \sigma$ represent the changes relative to the coordinate axes at either loop tip. As shown in Fig. 2, a reasonably good agreement exists between the experimental and simulated results for the stable hysteresis loop in tension at all of the current strain amplitudes other than $0.35 \%$. The experimental and simulated results obtained for the monotonic

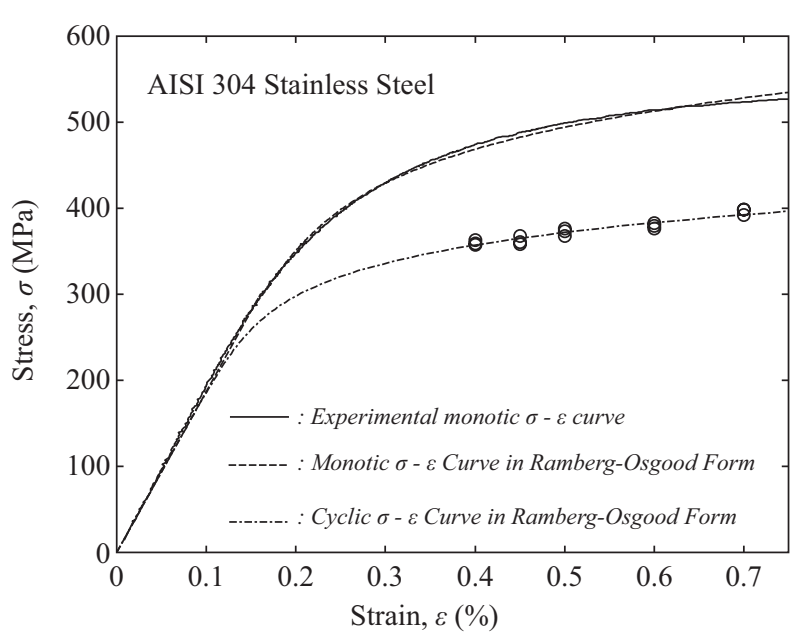

Fig. 6. Comparison of experimental and simulation results for monotonic and Massing cyclic stress-strain curves for AISI 304 stainless steel.

tensile stress-strain curve and the Massing cyclic stress-strain curve are presented in Fig. 6. It is apparent that a good agreement exists between the simulated and experimental curves. It can also be seen that the monotonic tensile stress strain curve lies above the cyclic stress strain curve, which indicates a cyclic softening effect in AISI 304 stainless steel.

\section{Effects of Non-zero Mean Strain on Strain-life Curve}

Figure 3 plots the strain-life curves for zero and non-zero mean strains obtained from a log-log linear regression analysis of the strain amplitude with respect to the corresponding number of cycles to failure. It can be seen that the degree of separation of the strain-life curves at different mean strain levels increases as the controlled strain amplitude reduces. This indicates that the degree of the imposed mean strain effect on the fatigue life becomes more significant at lower strain amplitudes, whereas the imposed mean strain has no obvious effect on the fatigue life at higher strain amplitudes.

On the basis of the experimental results presented in Tables 2 and 3 , it is found that the mean stress relaxes to approximately zero at higher strain amplitudes. This indicates that the fatigue life is not obviously affected by the applied mean strain when a stable nearly zero mean stress exists. However, in some cases, the stable mean stress is not fully relaxed and hence the effect of the mean strain on the fatigue life becomes more pronounced. Therefore, the stable mean stress induced by cyclic straining with an applied mean strain dominates the applied mean strain in terms of its effect on the fatigue life of AISI 304 stainless steel.

\section{Comparison of Experimental and Predicted Results Based on SWT Model}

This study uses the conventional SWT parameter, $\sigma_{\max } \varepsilon_{a}$, to predict the life of AISI 304 stainless steel subjected to cyclic deformation with mean strain. The corresponding calculated 


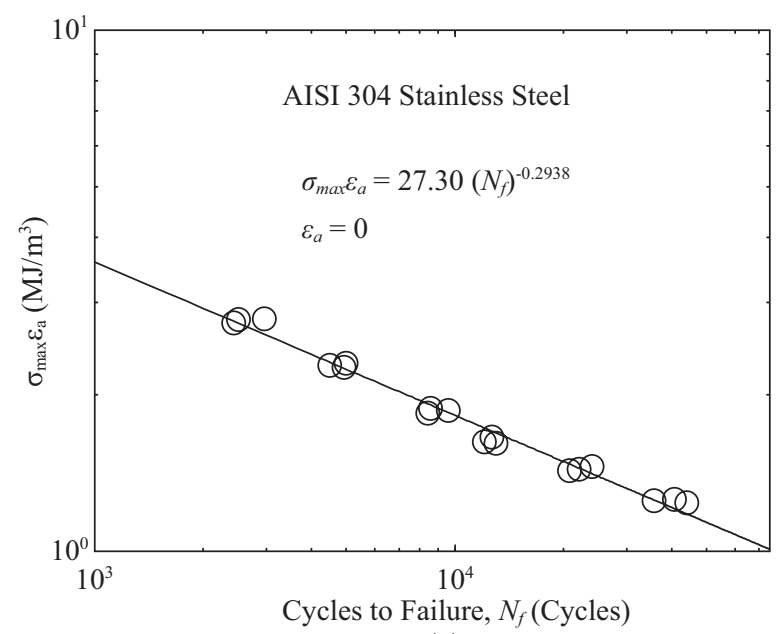

(a)

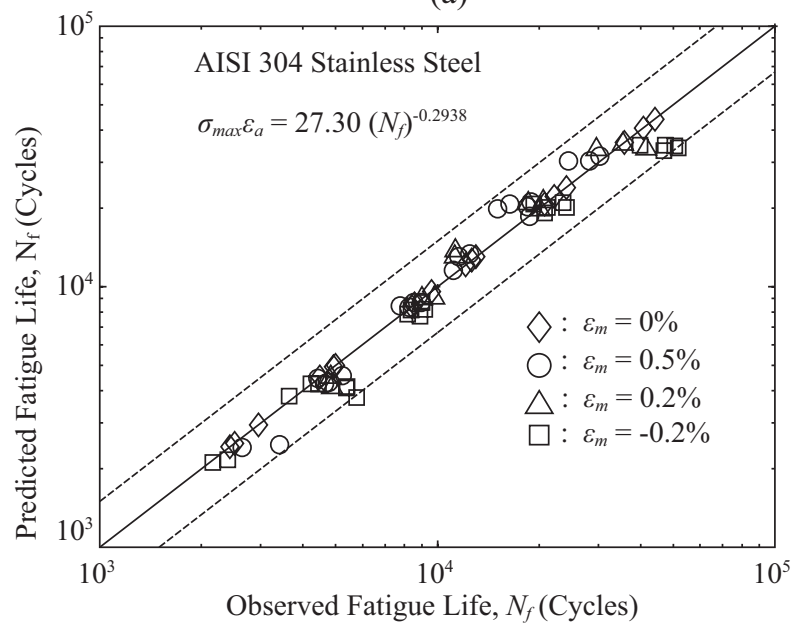

(b)

Fig. 7. (a) Data and least-squares fitted line for SWT parameter, $\sigma_{\max } \varepsilon_{a}$, versus cycles to failure, $N_{f}$. (b) Comparison of experimental and predicted fatigue life from (4).

results of $\sigma_{\max } \varepsilon_{a}$ for each fatigue test are presented in Tables 2 and 3. In applying the SWT model to fatigue life predictions, a fatigue life curve based on the SWT parameter for fully-reversed cyclic loading is necessary constructed. From the experimental data presented in Table 2, the least-square fitted line for AISI 304 stainless steel based on the SWT parameter is found to be:

$$
\sigma_{\max } \varepsilon_{a}=27.30\left(N_{f}\right)^{-0.2938}
$$

As shown in Fig. 7(a), it can be seen that there is a reasonable fit of the experimental data points. Subsequently, Eq. (4) can also be used to predict the effect of the mean strain on the fatigue life, $N_{f}$, of AISI 304 stainless steel for the $\sigma_{\max } \varepsilon_{a}$ values presented in Table 3. Figure 7(b) compares the predicted life results with the corresponding experimental results. It can be seen that most of the data points fall within a factor of two scatter bands. It is observed that the predicted data relating to the compressive mean strain effect have a rela-

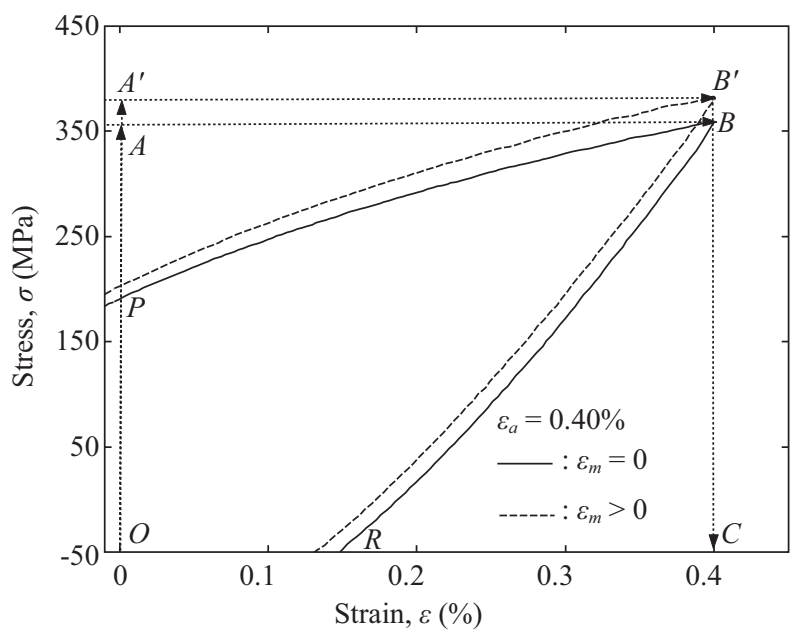

Fig. 8. Schematic illustration of change in parameter $\sigma_{\max } \varepsilon_{\mathrm{a}}$.

tively larger scatter than those relating to the tensile mean strain effect. Consequently, it can be inferred that the SWT model provides satisfactory life predictions for AISI 304 stainless steel under cyclic loading with a mean strain effect.

\section{Effect of Plastic Strain Energy on SWT Model}

Figure 8 plots two stable hysteresis loops obtained from fatigue tests performed with non-zero mean strain and zero mean strain, respectively, at the same strain amplitude. The two loops are deliberately plotted with shifted axes such that their strain amplitude ranges coincide. The area within a rectangle whose origin lies at point $O$, e.g. $O A B C$, represents the strain energy and can be regarded as the magnitude of the SWT parameter. Meanwhile, the area enclosed within the curve $O P B R O$ in Fig. 8 the plastic strain energy density, $\left(\sigma_{\max } \varepsilon_{a}\right)_{p}$, in the SWT parameter. In the low cycle fatigue regime, it is observed that the plastic term $\left(\sigma_{\max } \varepsilon_{a}\right)_{p}$ is more pronounced and plays a key role in determining the fatigue life. From the SWT model perspective, the area within the rectangle $A A^{\prime} B B^{\prime}$ ' in Fig. 9 represents the difference in strain energy density caused by the presence of stable tensile mean stresses induced by low cycle fatigue testing with a non-zero mean strain level. Hence, this study also generates fatigue life predictions for AISI 304 stainless steel using the conventional SWT damage parameter when a mean strain or stress effect is present. Furthermore, the results are then compared to those obtained using the fatigue parameter $\left(\sigma_{\max } \varepsilon_{a}\right)_{p}$ in order to investigate the role of the fatigue parameter $\left(\sigma_{\max } \varepsilon_{a}\right)_{p}$ in low cycle life estimations.

As in (4), a fatigue life curve relating the parameter $\left(\sigma_{\max } \varepsilon_{a}\right)_{p}$ to the corresponding fatigue life, $N_{f}$, via a coefficient and an exponent can be derived. As before, the values of the coefficient and the exponent are established using the least-squares technique. From the experimental data presented in Table 2, the fatigue life curve based on $\left(\sigma_{\max } \varepsilon_{a}\right)_{p}$ for AISI 304 stainless steel is found to be: 


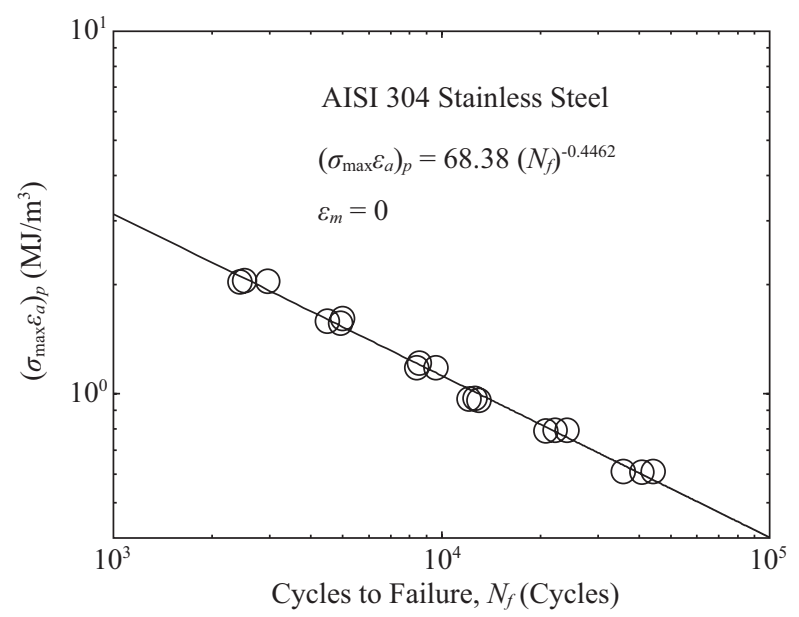

(a)

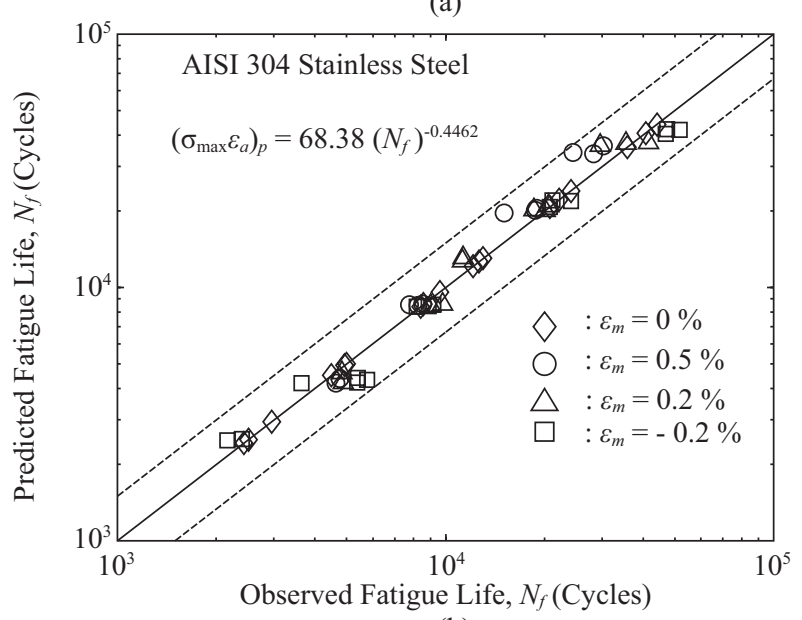

(b)

Fig. 9 (a) Data and least-squares fitted line for damage parameter, $\left(\sigma_{\max } \varepsilon_{a}\right)_{p}$, versus cycles to failure, $N_{f}$. (b) Comparison of experimental and predicted fatigue life from (5).

$$
\left(\sigma_{\max } \varepsilon_{a}\right)_{p}=68.38\left(N_{f}\right)^{-0.4462}
$$

Figure 9(a) shows that a good agreement exists between the solid line obtained using (5) and the measured data acquired from the current fully-reversed fatigue tests. Equation (5) can be used to predict the fatigue life data corresponding to the values of $\left(\sigma_{\max } \varepsilon_{a}\right)_{p}$ presented in Table 3. Figure 9(b) plots the calculated fatigue life results against the measured fatigue life data. It is clear that (5) provides reasonable fatigue life predictions for AISI 304 stainless steel.

In order to establish which of the two damage parameters provides the better prediction performance, this study applied a simple statistical procedure to calculate the standard deviation of the fatigue life prediction errors of the two damage parameters. The standard deviation of the prediction errors was calculated as:

$$
\Pi=\sqrt{\sum_{i=1}^{n} \frac{\left(\Delta_{i}-\bar{\Delta}\right)^{2}}{n-1}}
$$

where $\Delta$ represents the difference between the predicted result and the experimental value, and $\bar{\Delta}$ is the average value of all calculated $\Delta$ for each presented in Table 3 . The calculated value of $\Pi$ for the SWT damage parameter is 4472 and for the fatigue parameter $\left(\sigma_{\max } \varepsilon_{a}\right)_{p}$ is 3301. Based on the calculated results for $\Pi$, it can be inferred that the $\left(\sigma_{\max } \varepsilon_{a}\right)_{p}$ parameter provides better life estimates than the $\sigma_{\max } \varepsilon_{a}$ parameter.

\section{CONCLUSIONS}

This paper has presented an experimental investigation into cyclic deformation behavior of AISI 304 stainless steel. Based on observations of the experimental results and simple statistical analysis, the following conclusions can be drawn:

1. At the strain amplitudes considered in this study, the cyclic stress response curves obtained for AISI 304 stainless steel exhibit either an initial cyclic hardening followed by softening, or continuous cyclic softening to fracture.

2. At strain amplitudes of $0.25 \%$ and $0.30 \%$, the cyclic stress response curves in compression are higher than those in tension. The existence of asymmetry in both curves indicates that the anisotropic mechanical response of AISI 304 stainless steel must be taken into consideration during cyclic deformation at low strain amplitudes. Moreover, both cyclic stress response curves in compression and in tension are found to be in good agreement other than the two strain amplitudes above.

3. The experimental results show that AISI 304 stainless steel exhibits Massing behavior at controlled strains amplitudes of higher than $0.35 \%$. The monotonic tensile stress strain curve lies above the Massing cyclic stress strain curve. This provides an indication of the cyclic softening characteristics of AISI 304 stainless steel.

4. The stress relaxation is determined by the combined effect of the strain amplitude component and the mean strain component. Additionally, the stable mean stress dominates the applied mean strain effect in determining the fatigue life.

5. Statistical analysis reveals that the fatigue life results obtained from the $\left(\sigma_{\max } \varepsilon_{a}\right)_{p}$ damage parameter are more accurate than those obtained from the conventional SWT damage parameter, $\sigma_{\max } \varepsilon_{a}$.

\section{REFERENCES}

1. Chen, X., Xu, S., and Huang, D., "A critical plane-strain energy density criterion for multiaxial low-cycle fatigue life under nonproportional loading," Fatigue \& Fracture of Engineering Material \& Structures, Vol. 22, pp. 679-686 (1999).

2. Chiou, Y. C. and Yip, M. C., "Effects of mean strain level on the cyclic stress-strain behavior of AISI 316 stainless steel," Materials Science and Engineering A354, pp. 270-278 (2003).

3. Dowling Norman E., Mechanical behavior of materials (2), Prentice-Hall (1993).

4. El-Madhoun, Y., Mohamed, A., and Bassim, M. N., "Cyclic stress-strain behavior of polycrystalline nickel," Materials Science and Engineering, 
Vol. 385, pp. 140-147 (2004)

5. El-Madhoun, Y., Mohamed, A., and Bassim, M. N., "Cyclic stress-strain response and dislocation structures in polycrystalline aluminum," Materials Science and Engineering, Vol. 359, pp. 220-227 (2003).

6. Ellyin, F., "Effect of tensile-mean-strain on plastic strain energy and cyclic response," Journal of Engineering Materials and Technology, Vol. 107, pp. 119-125 (1985).

7. Golos, K. M., "Multiaxial fatigue criterion with mean stress effect," International Journal of Pressure Vessels and Piping, Vol. 69, pp. 263-266 (1990).

8. Golos, K. M. and Ellyin, F., "A total strain energy density theory for cumulative fatigue damage," Journal of Pressure Vessel Technology, Trans ASME, Vol. 110, pp. 36-41 (1988).

9. Gupta, C., Chakravartty, J. K., Reddy, G.R., and Banerjee, S., "Uniaxial cyclic deformation behaviour of SA 333 Gr 6 piping steel at room temperature," International Journal of Pressure Vessels and Piping, Vol. 82, pp. 459-469 (2005).

10. Hopperstad, O. S., Langseth, M., and Remseth, S., "Cyclic stress-strain behaviour of alloy AA6060," part I: uniaxial experiments and modeling, International Journal of Plasticity, Vol. 11, pp. 725-739 (1995).

11. Kliman, V. and Bi'ly', M., "The influence of mode, mean value and frequency of loading on the cyclic stress-strain curve," Materials Science and Engineering, Vol. 44, pp. 73-79 (1980).

12. Koh, S. K., "Fatigue damage evaluation of a high pressure tube steel using cyclic strain energy density," International Journal of Pressure Vessels and Piping, Vol. 79, pp. 791-798 (2002).

13. Kwofie, S., "An exponential stress function for predicting fatigue strength and life due to mean stresses," International Journal of Fatigue, Vol. 23, pp. 829-836 (2001).

14. Li, C., Ying, S., Shen, B., Qiu, S., Ling, X., Wang Y., and Peng, Q., "Cyclic stress-strain response of textured Zircaloy-4," Journal of Nuclear Materials, Vol. 321, pp. 60-69 (2003).

15. Lin C. K. and Pai, Y. L., "Low-cycle fatigue of austempered ductile irons at various strain ratios," International Journal of Fatigue, Vol. 21, pp. 45-54 (1999).
16. Luka's' P. and Kunz, L., "Effect of mean stress on the cyclic stress-strain response and high cycle fatigue life," International Journal of Fatigue, Vol. 11, pp. 55-58 (1988).

17. Mateo, A., Girone's, A., Keichel, J., Llanes, L., Akdut, N., and Anglada, M., "Cyclic deformation behavior of superduplex stainless steels," $M a$ terials Science and Engineering, Vol. 314, pp. 176-185 (2001).

18. Meininger, J. M., Dickerson, S. L., and Gibeling, J. C., "Observations of tension/compression asymmetry in the cclic deformation of aluminum alloy 7075," Fatigue \& Fracture of Engineering Material \& Structures, Vol. 19, pp. 85-97 (1996).

19. Morrow,J.D., Fatigue Design Handbook-Advances in Engineering, Warrendale, PA: Society of Automotive Engineers Vol. 4, pp. 21-29 (1968).

20. Perov, S. N., Ogarevic V. V., and Stephens, R. I., "Application and verification of fatigue life calculation methods for AZ91E-T6 cast magnesium alloy under variable amplitude loading," Journal of Engineering Materials and Technology, ASME, Vol. 115, pp. 385-390 (1993).

21. Samuela, K. G., Ganesana, V., Bhanu, S., Rao, K., Mannan, S. L., and Kushwaha, H. S., "Strain controlled LCF behaviour of SA-333 Gr 6 piping material in the range 298-673 K," International Journal of Pressure Vessels and Piping, Vol. 81, pp. 973-981 (2004).

22. Smith, K. N., Watson. P., and Topper, T. H., "A stress-strain function for the fatigue of metals," Journal of Material, Vol. 5, pp. 767-578 (1970).

23. Srivatsan, T. S. and Annigeri, R., "An investigation of cyclic plastic strain response and fracture behavior of steel-based metal-matrix composites," Engineering Fracture Mechanics, Vol. 56, pp. 451-481 (1997).

24. Vared, L. V. and Spinelli, D., "Fatigue, monotonic and fracture toughness properties of a Cr-Mn-N steel," International Journal of Fatigue, Vol. 23, pp. 857-863 (2001).

25. Wehener, T. and Fatemi, A., "Effects of mean stress on fatigue behavior of a hardened carbon steel," International Journal of Fatigue, Vol. 13, pp. 241-248 (1991).

26. Xia, Z., Kujawski, D., and Ellyin, F., "Effect of mean stress and ratcheting strain on fatigue life of steel," International Journal of Fatigue, Vol. 18, pp. 335-341 (1996) 